\title{
SENTIDOS DO COMBINAR E COMPARTILHAR: DESIGUALDADES E SITUAÇÕES DE VULNERABILIDADE DE MULHERES NA PECUÁRIA FAMILIAR
}

\author{
Tatielle Belem Langbecker* \\ Marta Júlia Marques Lopes**
}

\begin{abstract}
Resumo
O artigo tem como objetivo apresentar e discutir condições de trabalho e das dinâmicas familiares na pecuária familiar que consubstanciam situações de vulnerabilidade e privação de direitos das mulheres participantes de uma pesquisa acadêmica. Também se dedica a mostrar situações que configuram diferentes tipos de violência sofrida. Teoricamente apresenta uma leitura com autoras e autores contemporâneos dedicados a pensar a divisão sexual do trabalho, assim como a violência no rural além de reflexões inspiradas no sociólogo francês Pierre Bourdieu. Baseou-se em uma pesquisa qualitativa, do tipo estudo de caso, em que se analisou conteúdo temático de 15 entrevistas. As categorias definidas e analisadas neste artigo foram: integração comunitária; distribuição e destino de renda e crédito agrícola. A discussão permitiu o entendimento de que alguns elementos estruturais do trabalho na pecuária e, certas dinâmicas familiares, são potenciais geradores de vulnerabilidades às mulheres confirmando a persistência de um sistema assimétrico e hierarquizado de relações de gênero. As análises apontam situações que sugerem a pertinência de novos olhares sobre as clássicas determinações masculinas da pecuária familiar, definidas pela autonomia econômica, qualificação profissional em áreas desconsideradas femininas, dentre outras.
\end{abstract}

Palavras-chave: Gênero. Pecuária familiar. Vulnerabilidades. Divisão sexual do trabalho.

\footnotetext{
* Mestre em Desenvolvimento Rural pela Universidade Federal do Rio Grande do Sul (UFRGS). Doutoranda em Extensão Rural pela Universidade Federal de Santa Maria (UFSM). E-mail: tatielle.belem@gmail.com

** Pós-Doutorado pelo Centre Régionel D’informations et de Prévention du Sida, CRIPS, França. Doutora em Sociologia pela Université de Paris VII. Docente no Programa de Pós-Graduação em Desenvolvimento Rural da Universidade Federal do Rio Grande do Sul (Fac/Economia/UFRGS).E-mail: marta@enf.ufrgs.br
} 


\section{Introdução}

A noção de multissetorialidade amplia a visão sobre as atividades desenvolvidas no rural e a multifuncionalidade dá vez às demais funções que estão inseridas no rural, além da produtiva, seja em cunho ambiental, ecológico e/ou social. No entanto, essas noções e a reconfiguração do foco surgem a partir da década de 1990, pois, até então, as políticas direcionadas ao desenvolvimento rural eram percebidas como solução para a visão que definia o rural como ambiente atrasado. (SCHNEIDER, 2010).

$\mathrm{O}$ redirecionamento partiu da mudança de perspectivas dos próprios pesquisadores das problemáticas do rural, das "transformações sociais, políticas e econômicas que se operaram em âmbito de Estado" e "dos atores da sociedade civil". Foram transições como estas que possibilitaram alguns redirecionamentos do debate sobre temáticas específicas do desenvolvimento rural, focando, por ora, no crédito para a agricultura familiar, apoio às questões territoriais, às ações afirmativas para jovens, mulheres (SCHNEIDER, 2010) e demais públicos omitidos pelo anterior escopo do desenvolvimento rural.

Como consequência, as realidades foram se revelando mais complexas do que se imaginava, o que se constata nos estudos sobre a realidade da mulher rural brasileira. Dentre as pesquisas que se ocuparam dos cenários de situações e condições vivenciadas pelas mulheres rurais, mesmo em distintos contextos socioculturais, parece que algumas problemáticas se replicam pelos múltiplos espaços geográficos. Os recortes do trabalho feminino em âmbito produtivo são desenhados por contornos que o indicam como sinônimo de ajuda subalternizando e desqualificando suas atividades (BRUMER, 2004).

É nesse contexto que este artigo tem como objetivo apresentar e discutir condições de trabalho e dinâmicas familiares na pecuária familiar, identificadas por intermédio de informações de pesquisa que consubstanciam situações de vulnerabilidade e privação de direitos das mulheres participantes situadas no interior do estado do Rio grande do Sul. Também se dedica a pensar situações de violência, consubstanciadas em narrativas, presentes nas falas das mulheres, abrangidas nas seguintes categorias de análise: distribuição e destino da renda, crédito agrícola e integração comunitária.

Para isso, foi necessário adotar a perspectiva de gênero, a qual é elemento estruturante das relações hierárquicas de sexo que estão baseadas nas assimetrias de poder entre homens e mulheres e que sustentam as formas concretas e simbólicas de dominação. Nesse sentido, o gênero como categoria de análise "fornece elementos para a compreensão de vivências relacionais das mulheres" (LOPES, 2015, p. 79), inclusive permitindo 
a compreensão de situações de violência. A violência, neste caso, não se restringe à interpessoal, nas relações afetivas e familiares, mas ao trabalho e ao plano dos direitos sociais.

Logo, elementos encontrados nas formas de distribuição e destino da renda da atividade pecuária familiar identificam situações que materializam as desigualdades de gênero e, consequentemente, tornam frágeis, as possibilidades de agência feminina sobre suas próprias formas de ação no trabalho e consequências dele. A autonomia sobre os rendimentos, fundamento básico para essa condição de agente é limitada.

É importante delinear do que se trata a pecuária familiar, atividade produtiva em que se inserem as mulheres em estudo. A pecuária familiar revela um modo tradicional de "fazer" pecuária que não corresponde à lógica de grandes propriedades rurais. Para Ribeiro (2009), trata-se de um tipo diferenciado de agricultura, ou melhor, "agricultores familiares que criam bovinos de corte", ou seja, os pecuaristas familiares.

Essas famílias apresentam características semelhantes entre si que as definem como categoria social: o trabalho familiar com algumas trocas de serviço e eventuais contratações, relações mercantis adaptadas às necessidades familiares e variáveis dentre os diferentes tipos de pecuaristas, a bovinocultura de corte como principal atividade desenvolvida, mas não necessariamente a principal fonte de renda (RIBEIRO, 2009).

Em termos históricos, os pecuaristas familiares surgem com o fracionamento das propriedades rurais originadas na distribuição das sesmarias no século XVIII. Esse fracionamento foi provocado em virtude da divisão de terras entre herdeiros e, também, por fatores externos às propriedades, por exemplo, políticas econômicas e agrícolas, desencadeando modificações nas estruturas produtivas de vários estabelecimentos, dentre os quais se encontram os pecuaristas familiares (SANDRINI, 2005).

Essas dinâmicas produtivas têm as suas origens histórica e cultural fundadas nas antigas estâncias de produção extensiva de bovinos de corte e com base no homem como condutor da atividade produtiva. Nesse sentido, Andreatta (2009) - ao estudar o perfil dos pecuaristas do Rio Grande do Sul - identificou os processos de gestão e tomada de decisão como marcadamente centralizador, no que cerne os processos administrativos relacionados aos diversos tipos de pecuária de corte. Assim, as decisões são "atribuições do chefe ou responsável pelo estabelecimento, estes majoritariamente do sexo masculino" (ANDREATTA, 2009, p. 149).

Esse contexto expressa especificidades encontradas em regiões de pecuária extensiva no Rio Grande do Sul, onde a desvalorização socioeconômica das mulheres, por exemplo, aponta um dos motivos para a intensa masculinização do campo (RAUBER, 2010), o que pode resultar em dificuldades para dar sequência aos processos de sucessão 
familiar, justificando este estudo. $\mathrm{Na}$ Serra do Sudeste, região em que o município em estudo - Encruzilhada do Sul -, apesar de apresentar produção agropecuária diversificada, situa-se a pecuária de corte extensiva é predominante e caracteriza-se como atividade símbolo e, ainda, apresenta um dos maiores índices de masculinidade no campo (RAUBER, 2010).

\section{Revisão teórica}

As violências contra as mulheres, assentadas nas assimetrias de poder baseadas no gênero no rural, adquirem inúmeros contornos. Geralmente, manifestam-se na divisão sexual do trabalho, nas discriminações em relação aos cuidados com a terra, nas desigualdades na posse de terras, na sobrecarga de trabalho, dentre outros fatores fundamentados nas hierarquias intrafamiliares construídas na base das desigualdades de poder homemmulher (COSTA; LOPES; SOARES, 2014).

As hierarquias intrafamiliares constituem uma forma de violência contra as mulheres distinta da praticada contra aos homens, pois estes sofrem violência, geralmente, a partir de pessoas desconhecidas, enquanto aquelas são vítimas, na maioria das vezes, de seus pais, maridos, tios, dentro do ambiente familiar (GUIMARÃES, 2006). Isso reafirma a violência contra as mulheres como resultante das assimetrias de poder persistentes, baseadas nas culturas de gênero construídas socialmente (COSTA, 2012).

No rural, além de as mulheres sofrerem com a invisibilidade de seu trabalho visto apenas como "ajuda", ao tratar das questões de violência a realidade também é "ocultada" - cita Lorenzoni (2007). A autora enfatiza as diferentes formas de violência contra as mulheres no rural, sendo, em um primeiro momento, perceptível e configurada na violência física. Nesse sentido, a autora explicita a violência de gênero/sexista, pela sobrecarga de trabalho, desvalorização pela pobreza e condição social, física, moral, verbal, psicológica, doméstica ou, até mesmo, pelo uso de agrotóxicos.

A violência de gênero explicita-se como a definição que engloba as demais situações de violência contra as mulheres, já que seu princípio está na construção social dos papéis feminino e masculino. $O$ feminino é submisso ao masculino, sustentando as desigualdades de gênero em todas as sociedades; a violência pela sobrecarga de trabalho diz respeito à tripla jornada do trabalho das mulheres e, por instituir-se na divisão dos papéis feminino e masculino, não as considera trabalhadoras (LORENZONI, 2007).

A violência pela condição social e pobreza refere-se às precárias condições do sistema educacional do campo, pelo recente reconhecimento de sua condição de trabalhadora. Há dificuldade de acesso à documentação e atendimento de cunho preconceituoso no que se refere à saúde. As violências, física, moral, verbal, psicológica e doméstica no ambiente rural 
geralmente compõem um ciclo com várias fases contemplando cada um dos tipos citados. Esse "conjunto" de violências é o mais recorrente no espaço intrafamiliar no rural (LORENZONI, 2007).

A violência pelo uso de agrotóxicos relaciona-se aos danos causados à saúde pelo uso de agroquímicos, muitas vezes com efeitos sistêmicos não determinados, os quais podem, ainda, desencadear, no período gestacional, sequelas no feto da mãe que se expõe a esses produtos.

Por fim, ocorrem a violência no campo propriamente dita e a violência institucional. A primeira é sofrida pelas famílias a partir do momento em que sua produção não é suficiente para a manutenção, desencadeando as lutas pela terra, política agrícola e reforma agrária; já a institucional se formaliza nas diferentes sociedades e organizações, pois assegura o bemestar de alguns e se reproduz na estrutura familiar, na educação, religiões e assim por diante (LORENZONI, 2007).

Entretanto, mesmo ao enfatizar a multiplicidade dos tipos de violência contra as mulheres encontrados no rural, esta se apresenta em um cenário de silêncios, pois o ambiente é culturalmente construído como masculino e machista. Nesse âmbito, as mulheres não são reconhecidas nem como trabalhadoras, nem como cidadãs. $\mathrm{O}$ contexto do enfrentamento à violência nesse meio é de extrema vulnerabilidade, pois há falta de espaços institucionais que cumpram o dever de apoiar as mulheres inseridas nessas situações, garantindo-lhes os direitos sociais (COSTA, 2012).

A análise da violência simbólica, abordada por Bourdieu (2002) em seus estudos sobre a dominação masculina, pode contribuir para o entendimento da invisibilidade das situações de violência de gênero no rural, já que esta é vista pelo autor como um exemplo evidente da "naturalização" da dominação masculina. A definição de violência simbólica retrata uma

[...] violência suave, insensível, invisível a suas próprias vítimas, que se exerce essencialmente pelas vias puramente simbólicas da comunicação e do conhecimento, ou, mais precisamente, do desconhecimento, do reconhecimento, ou, em última instância, do sentimento. (BOURDIEU, 2002, p. 6-7).

Essa forma de violência utiliza instrumentos sutis de dominação e exclusão social, adotados por indivíduos, grupos e instituições (GOMES, 2008). A dominação masculina configura-se como uma das principais "fontes" da violência simbólica, pois o poder atribuído aos homens sobre as mulheres é reconhecido em todas as sociedades. Esta forma de dominar, assentada na subjetividade, passa a objetivar-se nas estruturas sociais que conduzem as atividades produtivas e reprodutivas baseadas na divisão sexual do trabalho e na reprodução biológica (BOURDIEU, 2002). 
Com isso, a construção social dos sexos transcende os acontecimentos históricos disseminando seus princípios universalmente. Nesse sentido, é percebida como uma matriz condutora das percepções, pensamentos e ações de todas as sociedades, incorporada pelos membros da sociedade e, implicando às mulheres a absorção da ideia de submissão assentada “[...] na incorporação dessas relações de poder e que se expressam nas oposições fundantes da ordem simbólica” (BOURDIEU, 2002, p. 44).

O medo e a vergonha de exposição das situações da violência vivenciadas, a dependência econômica e emocional, a cultura e a religião, sentimento de impotência frente ao poder masculino são alguns dos motivos explicitados pelas mulheres para estas se manterem em silêncio. Para Lorenzoni (2007), essas condições contribuem para a reprodução cultural dessa lógica, assim como evidenciam que a violência é uma maneira de controle social sobre a vida das mulheres.

\section{Caminhos percorridos: procedimentos da pesquisa}

Este artigo é um extrato de três categorias analíticas desenvolvidas em dissertação que trata sobre gênero e a divisão sexual do trabalho na pecuária familiar desenvolvida no Programa de Pós-Graduação em Desenvolvimento Rural da UFRGS. Após a definição do objeto de estudo, a situação das mulheres nas atividades de trabalho na pecuária familiar, decidiu-se o método e os procedimentos a serem desenvolvidos. A afirmação se baseia em Flick (2004); os procedimentos destacam as características de estudos qualitativos.

Nessa perspectiva, esta pesquisa delineou-se como estudo de caso, conforme explica Gil (2008). Assim, pensou-se que apresentar o cenário interativo, onde se desenrolam as situações de vida e trabalho das mulheres rurais estudadas, tornar-se-ia viável e rico em elementos compreensivos dessa dinâmica.

A aproximação com as participantes da pesquisa se deu em momento prévio junto à Empresa de Assistência Técnica e Extensão Rural (EMATER/RS) do município de Encruzilhada do Sul, sendo possível verificar a existência de mulheres inseridas nas atividades de trabalho da pecuária familiar e atestar seus interesses em participar da pesquisa. $\mathrm{Na}$ sequência, foram agendadas duas entrevistas-piloto no intuito de avaliar o instrumento de pesquisa.

Posteriormente, o estudo finalizou-se com 15 entrevistas, contando com as duas entrevistas-piloto que, devido à sua qualidade, não foram excluídas das análises. A saturação dos dados foi a maneira como se identificou o "limite" de participantes, isto é, “[...] quando as concepções, 
explicações e sentidos atribuídos pelos sujeitos começam a ter uma regularidade de apresentação" (DESLANDES, 2007, p. 48).

A organização e a interpretação dos dados e informações geradas foram realizadas por meio da análise de conteúdo temático proposta por Bardin (1979). Resumidamente, desenvolveram-se as três principais etapas realizadas para se obter uma análise de conteúdo (CAMPOS, 2004).

As unidades de análise traduziram-se em "estrutura de trabalho e dinâmicas familiares" e "vulnerabilidades e violências de gênero", expressando os núcleos de sentidos dos processos teórico e metodológico, e identificadas em frases, palavras, sentenças representativas de algum sentido para o objeto investigado. Por fim, as unidades de análise foram identificadas por categorias, as quais foram compostas por variáveis temáticas.

Esse processo metodológico desdobrou-se em mais de 20 categorias de estudo (Figura 1) sendo 12 classificadas na unidade de análise "estruturas de trabalho e dinâmicas familiares" e oito em "vulnerabilidades e violência de gênero". Na categoria "pecuária" ainda houve uma terceira subdivisão contemplando as subcategorias "aspectos positivos, aspectos negativos, motivações, o "ser mulher” na pecuária e opinião sobre a definição".

Figura 1 - Estrutura de análise e suas categorias analíticas

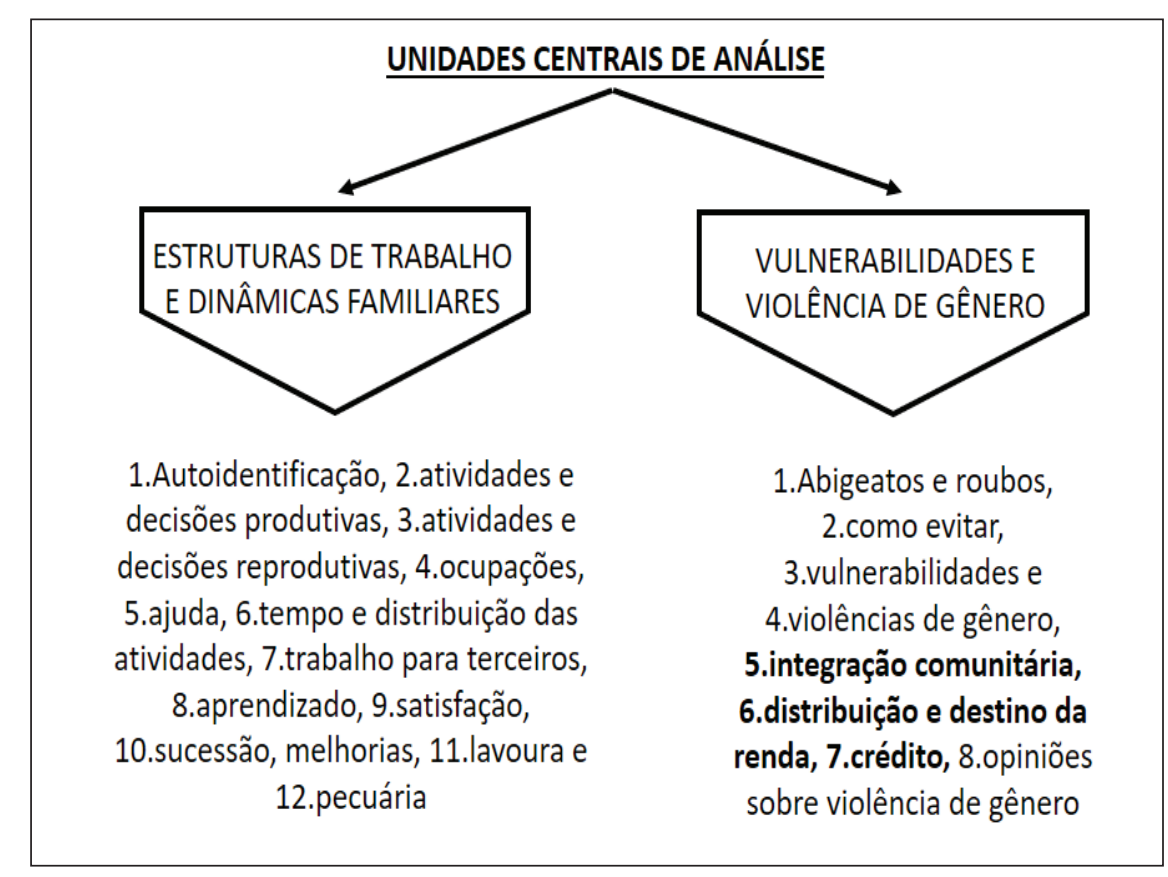

Fonte: Elaborada pelos autores (2018).

As categorias 5, 6 e 7 classificadas na unidade central de análise "vulnerabilidades e violência de gênero" são as exploradas neste artigo. 


\section{Resultados e discussão}

Com base nas escolhas teóricas e nas categorias analíticas empíricas apresentadas, mostra-se o quão é sutil e como, ao mesmo tempo, escancaram-se as situações que materializam as desigualdades de gênero e, consequentemente, fragilizam as possibilidades de agência feminina. A autonomia sobre os rendimentos, fundamento básico para essa condição de agente é limitada. A renda obtida com a produção destina-se, majoritariamente, para suprir as necessidades da produção, da casa e da família como constatado nas falas das entrevistadas:

Tudo sai daqui, né? A nossa despesa, a nossa despesa pessoal, e tudo fica aqui também, porque é o custo com os animais, é o custo com a lavoura. Então, a renda é toda voltada pra cá e nos manter né. (Entrevistada 3).

Quando a gente consegue vender é pra gente pagar uma conta de luz. A gente compra alimentação, né? Quando precisa, compra coisa pro guri [filho] ir pro colégio e, assim, essas funçôes aí. (Entrevistada 13).

A administração da renda é responsabilidade do marido ou do casal. Apenas uma entrevistada mencionou estar à frente da administração da renda da propriedade, mais especificamente a Entrevistada 1, que apresenta situação de viuvez recente. A Entrevistada 10, também viúva, não responde pela renda da venda dos animais, e sim, seu filho; em contrapartida, tem autonomia sobre seus ganhos com os benefícios das duas aposentadorias que recebe.

Nesse sentido, além do protagonismo masculino estar vinculado aos espaços públicos e produtivos no ambiente interno, familiar, a presença e participação do homem replica seus papéis no externo, ou seja, as decisões constituídas como "mais importantes" são realizadas por eles, ainda mais em se tratando da renda advinda do trabalho agropecuário. Lunardi (2012) verifica situação semelhante, visto que, ao pesquisar relações de gênero no turismo rural, identificou que os homens são os responsáveis pela geração de renda e gastos agrícolas; assim, os recursos oriundos destas atividades são de domínio masculino. Barbosa (2013) também conclui que a responsabilização sobre os recursos oriundos das atividades agropecuárias é, principalmente, designação masculina.

É ele [marido]. E alguma coisa a gente compartilha. (Entrevistada 5).

Ah, é nós dois, tanto ele quanto eu. É o marido e a mulher, tem que ser combinado, se está sobrando pra uma coisa vai pra aquilo. (Entrevistada 6).

É o meu marido. A gente combina, e ele que resolve. (Entrevistada 9). 
O “combinar", assim como o "compartilhar", ganha caráter de "estar em acordo" com determinada decisão econômica tomada pelos homens em maioria maridos; então, na pecuária, quando as mulheres comentam que combinam com os maridos, "[...] isso quer dizer que, na maioria das vezes, eles conversam sobre, porém, quem tem a palavra final é o homem" (LUNARDI, 2012, p. 137). A falta da participação feminina em processos decisórios em dinâmicas familiares rurais, especialmente na pecuária familiar, atesta as construções sociais sustentadas nas assimetrias de gênero, criando barreiras culturais assentadas nas naturalizações (BARBOSA, 2013) do ser homem e ser mulher, demarcando as mulheres aos trabalhos domésticos e os homens como porta-vozes e chefes de família.

Assim, é possível afirmar que as culturas de gênero calcadas nos "papéis tradicionais" naturalizados, explicam as dificuldades vivenciadas pelas mulheres em participar de forma concreta dos processos decisórios das unidades familiares rurais. Pensando nisso e, considerando que no Brasil há uma estreita relação entre vulnerabilidade social e violência simbólica (BOURDIEU, 2002), observa-se que as situações cotidianas das mulheres pecuaristas, principalmente direcionadas às dinâmicas produtivas internas à família, permeiam o que Abramovay e Pinheiro (2003, p. 2) entendem por "violência simbólica". Os autores referem à violência simbólica como "[...] abuso do poder baseado no consentimento que se estabelece e se impõe mediante o uso de símbolos de autoridade" e exemplificam-na pela violência verbal e institucional. Contudo, considerando o poder concedido aos homens a partir da constituição social do gênero e analisando as falas das entrevistadas, pode-se afirmar que, embora haja mudanças, as mulheres permanecem submetidas à violência simbólica das tradições culturais dominantes, o que potencializa a vulnerabilidade socioeconômica feminina nos espaços público e privado.

Em relação à renda distribuída diretamente às mulheres, quatro das entrevistadas mencionaram não receber nenhuma espécie de rendimentos financeiros. Em um primeiro momento, esta informação parece ser satisfatória, considerando o total de mulheres entrevistadas, e impulsiona o entendimento pelo empoderamento econômico feminino. Entretanto, a diversidade das fontes de renda das mulheres (aposentadoria, benefícios sociais, venda de animais, venda de produtos caseiros e serviços) e sua destinação põem em discussão alguns elementos que "limitam" o poder socioeconômico das mulheres inseridas na pecuária familiar.

É pra comprar alguma coisa pra mim, pra guria ou pra nós mesmo, pra casa. Acaba indo tudo pra família; assim, não tem uma coisa [especifica]. (Entrevistada 4).

Ah, eu movimento assim pra casa, ajudo o meu esposo a comprar as coisas. É tudo pra casa. (Entrevistada 8). 
Mais é pra ajudar, eu me trato também com um médico. Agora mesmo, ontem, eu fui consultar... As consultas são muito caras, né? Ee mais os remédios. Eu sei que eu pago a consulta, eu pago o remédio e o dinheiro vai, né? (Entrevistada 11).

Parte considerável das entrevistadas utilizam suas rendas pessoais para as responsabilidades domésticas, atribuindo o sentido de "ajuda ao marido" como contas a pagar, alimentação, roupas, medicamentos, demais serviços e mercadorias relacionados aos cuidados com o lar, compatíveis com as atribuições femininas. Com o direcionamento de seus rendimentos aos gastos com a manutenção da casa e família, ocorre a reafirmação da mulher como protagonista da esfera reprodutiva, cabendo ao homem "as funções com maior valor social adicionado" ocupadas no espaço produtivo (HIRATA; KERGOAT, 2007, p. 599).

Ainda assim, algumas participantes mencionam a concretização de aquisições pessoais, indicando possibilidades de empoderamento econômico feminino e não somente em virtude de suprimentos relacionados à extensão de suas atividades cotidianas. Embora com nuances de mudanças no sentido de investimentos pessoais por parte das mulheres, a maioria destina seus rendimentos para a casa e a família. No turismo rural essa situação se replica, porque, parafraseando Lunardi (2012, p. 122), já que as mulheres são responsabilizadas pela manutenção da família e os homens da produção, "os recursos oriundos e destinados a cada estrutura estão relacionados a essa divisão", ou seja, recursos da renda feminina vão para a casa e recursos da renda masculina, para a produção.

$\mathrm{O}$ acesso ao crédito rural também se constitui como elemento potencial para analisar as estruturas de trabalho e dinâmicas familiares que consubstanciam desigualdades que se traduzem em vulnerabilidades, fragilidades, para as mulheres. As entrevistadas que não realizaram operações de crédito totalizam nove participantes; destas, em cinco relatos, nenhum membro de sua família acessou financiamentos, enquanto, segundo o relato das outras quatro entrevistadas, os maridos já acessaram, como pode ser percebido nas seguintes falas:

[...] Nessa parte eu sou zero. Eu não tenho nenhuma noção dessas coisas, assim, sabe? porque a gente nem, nem faz crédito assim no banco, coisa assim, né? (Entrevistada 5).

Nem sei mesmo te dizer esse negócio de crédito não. (Entrevistada 6).

Essa característica é recorrente em alguns pecuaristas familiares; afinal, conforme afirma Ribeiro (2009), parte desta categoria social rejeita quaisquer relações com empréstimos bancários e, inclusive, orgulham-se em não manterem dívidas. Isso confirma a importância que os pecuaristas 
familiares dão à sua autonomia financeira e mercantil, considerando como prioridade as necessidades familiares e não o lucro. Em contrapartida, algumas entrevistadas comentam que a contração de operações de crédito é realizada pelos maridos.

Meu marido, mais é com ele que usa assim, negócio de PRONAF... No meu nome eu não tenho nada. Estou encaminhando pra começar... Eu ajudo, a gente paga em conjunto e coisa, né? Mas ele é que, enquanto ele está tendo limites né, ele vai fazer né, porque está tudo encaminhado. Ele chega lá nos bancos. Lá, os caras já conhecem ele, sabem que, então é mais fácil, né? Quando precisar, aí eu comę̧o. (Entrevistada 4).

O processo de negociação e as atividades de financiamento que envolvem a presença no banco, frequentemente são consideradas "negócio de homem”, pois estes teriam mais contato com os agentes bancários, facilitando, assim, a concessão de crédito, como pode ser observado na fala da entrevistada quatro. Assim, o "facilitar" o processo exclui as mulheres de alguns ambientes públicos, tornando a presença feminina praticamente inexistente em agências bancárias, ainda mais por serem mulheres rurais.

Hernandez (2009) questionou determinada política de crédito com o intuito de verificá-la como meio para o empoderamento de mulheres rurais. Os aspectos burocráticos e a presença no banco foram alguns dos fatores que a autora identificou como novos para as mulheres, já que antes da modalidade de crédito destinada às mulheres, eram os homens os únicos "frequentadores" do banco. Alguns agentes bancários confirmaram a predominância masculina nas agências bancárias, e as próprias mulheres reconhecem como "papel" masculino as negociações e esse tipo de atividades.

Esse reconhecimento "natural" pelas mulheres em afirmar os homens como principais agentes de operações bancárias, e assim nas demais atividades públicas e produtivas, exemplifica o que Bourdieu (2002) diz sobre a afirmação da primazia masculina nas objetividades das estruturas sociais e de atividades produtivas e reprodutivas. $\mathrm{O}$ argumento acerca dessas relações (masculino/feminino) recai sobre a reprodução biológica e social que confere aos homens a dominância de espaços públicos e funcionam como "[...] matrizes das percepções, dos pensamentos e das ações de todos os membros da sociedade, como transcendentais históricos que, sendo universalmente partilhados, impõem-se a cada agente como transcendentes" (BOURDIEU, 2002, p. 45). Assim, as próprias mulheres incorporam sistemas de pensamentos produzidos pelas relações de poder entendendo sua subordinação como natural, ou seja, nada mais "natural" que ser o homem o responsável por atividades bancárias, pois desde que se tem conhecimento "sempre" foi ele quem resolveu estas questões.

Apesar de a realidade permear situações promotoras de vulnerabilidades socioeconômicas em relação às mulheres, seis entrevistadas 
relataram serem as titulares em algumas operações de crédito, por exemplo, o PRONAF e empréstimos com cartão de crédito. Ainda que a titularidade contribua para o reconhecimento das mulheres proporcionando confiança e segurança, como afirma Hernandez (2009), há que se analisar o contexto que promove a decisão da mulher (ou de familiares, especialmente o marido) em realizar operações financeiras. Dessa forma, encontraram-se situações diversas no que se refere à titularidade das mulheres em operações de crédito.

Eu trabalhava com o PRONAF. E, aí, depois, quando eu perdi meu marido, eu cancelei lá... No meu nome, assim como é que é, é o custeio que eles largavam, tanto fazia ser homem ou mulher, era o mesmo. (Entrevistada 1).

Desde 2002, desde 2000 a gente tem; mas, desde 2002, eu faço os meus créditos rurais... Eu não tenho vergonba de dizer que dependo do crédito pra manter a lavoura, principalmente que é o que tem o custo mais alto, né? Mas também tenho orgulho em dizer que até hoje não atrasei nunca minhas contas. (Entrevistada 3).

Eu faço empréstimo. Eu dei uma moto zero pra ele [filho]. Agora ele comprou um trator. Também fiz um empréstimo... Também foi com um empréstimo do meu cartão. A gente trabalha com isso. Mas, assim, olha, dívida é no meu cartão. Nós não temos dívidas, nem eu nem ele. Nossa dívida é no meu cartão. (Entrevistada 10).

A Entrevistada 1 afirma que, antes do falecimento de seu marido, trabalhava com operações de crédito destinadas ao custeio da produção e inclusive salienta que a modalidade acessada era concedida independentemente de ser homem ou mulher. No entanto, com o falecimento do marido, revela que cancelou as operações realizadas, remetendo ao entendimento de que a responsabilização pela produção com fins econômicos era dele. As atividades relacionadas à criação passaram a ser responsabilidade de seu filho e suas necessidades são supridas exclusivamente com fundos de sua aposentadoria.

Isso exemplifica, claramente, a separação entre atribuições femininas e masculinas na pecuária familiar, já que as operações de crédito eram realizadas exclusivamente em vida de seu marido, mesmo que em nome da mulher. Refletindo a partir de Kergoat (1996, p. 22), a situação recente de viuvez da entrevistada permite identificar o que autora salienta sobre as formas de pensar do dominado, pois "uma mulher não se pensa como mulher, ela se pensa também dentro de uma rede de relações sociais", como trabalhadora, mãe, jovem ou velha, sempre concorde com sua posição de dominada nas diferentes relações sociais. Assim, a afirmação do homem 
dominante decorre da posição ocupada pelo dominado, onde este se legitima como tal. A desistência da entrevistada em prosseguir operações de crédito e entregar sua produção ao filho pode ser interpretada como afirmação de sua condição dominada, pois se submete ao pensamento proveniente de sua condição de viúva, e não de mulher como potencial agente na continuidade dos negócios, estabelecendo os lugares de homem e de mulher.

Já a Entrevistada 3 destacou realizar operações de crédito há mais de dez anos principalmente direcionados à lavoura, pois a pecuária necessita de menos insumos. Além de relatar sua longa relação com a pecuária, ela demonstra utilizar-se mais da lógica econômica do que a maioria das participantes. No decorrer de sua entrevista, estabelece a divisão de atividades: seu marido estaria mais envolvido com a agricultura e ela com a pecuária; logo, subentende-se a lógica econômica em investir na agricultura, já que esta demanda mais insumos em função de seu retorno financeiro ser mais rápido.

Um terceiro depoimento revela a realização de empréstimo para seu marido com a finalidade de pagamento de uma dívida. E em um momento seguinte, a Entrevistada 10, comenta trabalhar, frequentemente, com empréstimos através de seu cartão de crédito para compras de produtos que consideram necessários. Assim, presenteou seu filho com uma moto, adquiriu um pequeno trator para facilitar a lida rural e o utiliza também em momentos de necessidades financeiras. Sua viuvez, como enfatizado pela própria entrevistada, contribuiu para a melhoria de sua qualidade de vida, possibilitando autonomia socioeconômica.

O poder simbólico talvez seja uma das principais formas de empoderamento alcançado por estas mulheres através da titularidade em operações de crédito. Hernandez (2009) relata que a possibilidade de estarem no banco para acessar um crédito permite a essas mulheres sentirem-se reconhecidas com maior confiança e segurança, assim como desenvolver certa independência e transitar em espaços públicos socialmente constituídos como masculinos. Porém, como destaca a autora, afirma-se que a presença feminina no banco se mostra como um aspecto normativo para a concessão do crédito, o que não "[...] necessariamente poder-se-ia garantir a continuidade e permanência para assumir a responsabilidade de lidar com os aspectos burocráticos, que emanam da lógica de operacionalização do crédito e que, muitas vezes, leva algumas mulheres a se desmotivarem" (HERNANDEZ, 2009, p. 170).

O processo de empoderamento e a construção do poder de agência (SEN, 2010) das mulheres através do acesso ao crédito, provavelmente, seja limitado, pois, como afirma Zorzi (2008), geralmente a decisão em acessar o crédito não é exclusivamente da mulher e, sem o consentimento dos maridos a efetivação da operação possivelmente não seria realizada. 
Os destinos dos créditos acessados pelas entrevistadas, na maioria, não inovam as atividades desempenhadas pelas mulheres. Isto também é retratado por Zorzi (2008), ao analisar o PRONAF Mulher, pois os projetos realizados complementam as tradicionais atividades femininas contribuindo na invisibilidade da mulher tanto no trabalho cotidiano, como na família. Assim, confirma-se, por meio dos aspectos analisados até então, que esses projetos não constituem elementos suficientes "[...] para ruptura de determinadas práticas sociais construídas e historicamente vinculadas aos homens e mulheres em suas contribuições para a reprodução social da agricultura familiar" (ZORZI, 2008, p. 74).

Corroborando com Kergoat (2010), parte das mudanças que parecem ser evidentes, por exemplo, o acesso das mulheres ao crédito, devem ser mais profundamente refletidas, pois em termos de relações intersubjetivas entre os sexos, ocorrem mudanças; porém, no que tange às relações e práticas sociais, essas mudanças não são tão efetivas. Se as mulheres conseguem acessar operações de crédito como titulares (fruto de mudanças nas relações intersubjetivas), não necessariamente este acesso seja provocado por mudanças efetivas no sistema dominante. Pelo contrário, ao observar a destinação dos créditos das entrevistadas, nota-se que as práticas e relações sociais de sexo permanecem, praticamente, intactas. Ou seja, créditos para o espaço produtivo dominado pelos homens.

Analisando a integração social das mulheres inseridas na pecuária familiar, quatro entrevistadas afirmaram não participar de associações, sindicatos, cooperativas ou algum grupo. Considerando o número de entrevistas essa ausência de participação é significativa. Destas quatro, uma mulher não participa de nada; para as demais, a única forma de integração social resume-se à participação em cursos e momentos proporcionados pelo serviço de extensão rural (EMATER) ou SENAR.

Não. Ai, quando tem, é assim, curso do SENAR, por exemplo, a gente participa. Esses da EMATER a gente participa. Mas, assim, ser associado mesmo não. Só assim os cursos que sai. Dai e gente forma um grupo e faz. Agora mesmo, a gente está, a gente fez uns quantos cursos do SENAR. E agora estamos fazendo o de guasqueiro, como dizem. Que eu adoro, eu adoro lidar com corda. (Entrevistada 5).

Só essas coisas da EMATER, esses programas da EMATER é que [participam]... Nós fomos até num dia de campo lá na Palma [localidade]. (Entrevistada B).

De modo geral, cursos que buscam alcançar o público feminino rural baseiam-se em atividades de artesanato, culinária e afins. Porém, a Entrevistada 5 destacou sua participação em um curso de guasqueiro, atividade tradicionalmente masculina da cultura gaúcha. Já a Entrevistada 
B comentou sobre sua participação em um dia de campo voltado à produção agropecuária. Nota-se que, embora pequena a participação dessas mulheres, observam-se mudanças, ainda que tímidas, no que tange à inserção da mulher em ambientes tipicamente masculinos. Isso pode relacionar-se talvez a aptidão da região para a pecuária que serve como incentivo para os órgãos promotores de ações deste tipo e contribuam para a participação e valorização das mulheres nestes espaços.

As mulheres que participam de sindicatos, associações e outros tipos de integração social apresentam diferentes motivações para inserirem-se.

É, a gente faz festa... É que a associação está tão assim atirada. Esse mês mesmo não saiu reunião, andou falecendo os pais da presidente. Então não querem fazer festa. Ah, mas tinha que fazer né, não sai nada aqui, mas está. A gente já fez alguma festinha (Entrevistada 9).

É muito bom, têm médicos, tem tudo quanto é coisa. A gente vai, né? Quando pode ajudar [financeiramente], a gente ajuda; quando não pode, não. Vai só participar, né? Tudo assim. (Entrevistada 13).

As dificuldades de acesso a serviços básicos públicos representam uma dessas motivações, pois a participação em associações aproximam as comunidades rurais, especialmente as mulheres aos serviços básicos como saúde e auxílios na busca pela previdência social. A realização de eventos que integrem a comunidade também motiva a participação em associações comunitárias rurais e possibilita a busca por menores custos e acesso a produtos de interesse comum às famílias, como insumos para a produção rural. E a isso se somam as motivações para inserção em associações e sindicatos, por exemplo.

Nesse sentido, salienta-se que o interesse pelas associações locais prende-se, muitas vezes, à privação de direitos, gerando como consequência a busca por alternativas aos serviços que deveriam ser oferecidos pelo poder público. As dificuldades geográficas e econômicas do rural privam as famílias, especialmente as mulheres, do uso de direitos básicos, como o acesso aos serviços públicos de saúde. Lopes (2015) observa que os serviços de atenção básica à saúde estão localizados nos centros urbanos, criando barreiras para o acesso das mulheres, esse fato atestando a complexidade das dinâmicas socioculturais encontradas no rural. Há resposta a esta situação quando as mulheres procuram se inserir em associações objetivando os auxílios e descontos oferecidos para acesso aos serviços privados visando, mesmo que de forma indireta, à redução das vulnerabilidades decorrentes desta deficiência (do "vazio" de direitos) encontrada no rural.

Os eventos realizados pelas associações acabam por representar as poucas oportunidades de lazer e divertimento das participantes. A falta de opções de lazer já é conhecida no rural, ainda mais ao referenciar as mulheres 
que, por vezes, mencionam não terem tempo para esses momentos, pois estariam envolvidas com suas atividades, ou seja, a sobrecarga de trabalho privaas do lazer (BARBOSA, 2013). E, ainda, como mencionou uma entrevistada, as mulheres geralmente se envolvem nos preparativos das festividades, o que as impede de aproveitarem os poucos momentos de diversão.

Mais uma vez, percebe-se o direcionamento das mulheres a condições e situações que se referem ao espaço reprodutivo, pois elas buscam inserção em organizações que irão de alguma forma "beneficiar" a família, especialmente no que diz respeito à saúde, ao lazer e acesso aos demais direitos, muitas vezes, dificultados às famílias rurais. $\mathrm{O}$ envolvimento com preparativos em festividades também pode ser interpretado como extensão de suas atividades cotidianas, domésticas; afinal, nesse momento, são realizadas tarefas de limpeza, preparação de alimentos e outras atividades comuns às mulheres.

Tedeschi (2013, p. 449) observou que a esfera doméstica (ambiente privado) é dotada de afetividades e vínculos emocionais que buscam interferir no alcance das necessidades subjetivas das pessoas, especialmente no que se refere à família. Nesse sentido, as atividades próprias do espaço privado e, consequentemente, delegadas às mulheres, ocupam o "plano da invisibilidade, negando qualquer possibilidade de valorização e reconhecimento social”. Verifica-se que essas atividades desvalorizadas, abrangem essencialidades para a manutenção da vida das pessoas, como pode ser visualizado pela busca feminina por meios que permitam o acesso à saúde pública, beneficiando a família como um todo. Tedeschi (2013) reforça que, dentre essas atividades invisíveis, incluem-se a alimentação e o afeto, fundamentais para estabilidade física e emocional dos membros da família, realizadas cotidianamente seja em casa ou em ambientes de socialização comunitária, como igrejas, associações de moradores, sendo desenvolvidas sem quaisquer remunerações.

\section{Questionar para não finalizar}

As situações referidas nas discussões mencionadas mesclam elementos estruturais do trabalho na pecuária e dinâmicas familiares que são potenciais geradores de vulnerabilidades às mulheres e confirmam a persistência de um sistema assimétrico e hierarquizado de relações de gênero, onde as mulheres submetem-se à lógica masculina dominante. Entretanto, podem ser consideradas situações que encaminham novos olhares sobre as determinações masculinas sobre a pecuária familiar, por exemplo, a autonomia econômica (mesmo considerando a viuvez como uma condicionante conhecida para o referido ganho), a realização de cursos que ultrapassem os limites das atividades tipicamente femininas, 
a expressão de pensamento lógico e produtivo delimitados anteriormente como masculinos, dentre outros.

As mulheres ainda apresentam reduzida participação nos momentos de decisão sobre as atividades agropecuárias, principalmente em função do caráter auxiliar que suas atividades representam às dinâmicas familiares rurais. Contudo, percebe-se que as atividades constituídas como masculinas também são desempenhadas, em várias situações, pelas mulheres, mantendo o trabalho doméstico como sua atribuição primária. Assim, entende-se que o "caráter complementar" do trabalho feminino, seja em casa ou no campo, define o poder de decisão dentro da pecuária familiar.

Com isso, remete-se a questionamentos, como: será que homens e mulheres, na pecuária familiar, efetivamente compartilham "alguma coisa" além dos lugares já tradicionais de gênero? A apropriação do espaço privado pelas mulheres limita sua participação em ambientes públicos ou são as culturas de gênero que bloqueiam seu efetivo envolvimento e reconhecimento em ambientes construídos como masculinos? A vida prática parece apontar para o exercício consciente de certas mudanças; no entanto, há que se apostar em transformações constantes nesse âmbito, garantindo às mulheres atuarem socialmente e particularmente no trabalho rural, com garantias da igualdade de direitos.

\section{Referências}

ABRAMOVAY, Miriam; PINHEIRO, Leonardo Castro. Violência e vulnerabilidade social. In: FRAERMAN, Alicia. Inclusión social y desarrollo: presente y futuro da la Comunidad Iberoamericana. Madri: Comunica, 2003.

ANDREATTA, Tanice. Bovinocultura de corte no Rio Grande do Sul: um estudo a partir do perfil dos pecuaristas e organização dos estabelecimentos agrícolas. 2009. 240 f. Tese (Doutorado em Desenvolvimento Rural) - Programa de Pós-graduação em Desenvolvimento Rural, Universidade Federal do Rio Grande do Sul, Porto Alegre, 2009.

BARBOSA, Ana Alves Neta. Mulheres na agricultura familiar do semiárido Norte-Mineiro: divisão social do trabalho e gênero no Projeto Jaíba. 2013. 223 f. Tese (Doutorado em Desenvolvimento Rural) - Programa de Pós-Graduação em Desenvolvimento Rural, Universidade Federal do Rio Grande do Sul, Porto Alegre, 2013.

BRUMER, Anita. Gênero e agricultura familiar: a situação da mulher na agricultura do Rio Grande do Sul. Estudos Feministas, v. 12, n. 1, p. 205-227, 2004.

BOURDIEU, Pierre. A dominação masculina. 2. ed. Rio de Janeiro: Bertrand Brasil, 2002.

BARDIN, Laurence. Análise de conteúdo. Lisboa: Edições 70, 1979.

CAMPOS, Claudinei José Gomes. Método de análise de conteúdo: ferramenta para a análise de dados qualitativos no campo da saúde. Revista Brasileira de Enfermagem, Brasília, v. 57, n. 5, p. 611-614, 2004. 
COSTA, Marta Cocco. Violência contra mulheres rurais, agendas públicas e práticas profissionais da saúde: o visível e o invisível na inconsciência do óbvio. 2012.317 f. Tese (Doutorado em Enfermagem) - Programa de Pós-graduação em Enfermagem, Universidade Federal do Rio Grande do Sul, Porto Alegre, 2012.

.; LOPES, Marta Júlia Marques; SOARES, Joannie dos Santos Fachinelli. Representações sociais da violência contra mulheres rurais: desvelando sentidos em múltiplos olhares. Revista da Escola de Enfermagem, p. 214-222, 2014.

DESLANDES, Suely Ferreira. O projeto de pesquisa como exercício científico e artesanato intelectual. In: DESLANDES, Suely Ferreira; MINAYO, Cecília de Souza. Pesquisa Social: teoria, método e criatividade. 26. ed. Petrópolis: Vozes, 2007.

FLICK, Uwe. Uma introdução à pesquisa qualitativa. 2. ed. Porto Alegre: Bookman, 2004.

GIL, Antonio Carlos. Métodos e técnicas de pesquisa social. 6. ed. São Paulo: Editora Atlas S.A., 2008.

GOMES, Romeu. A dimensão simbólica da violência de gênero: uma discussão introdutória. Athenea Digital. Instituto Fernandes Figueira da Fundação Oswaldo Cruz, n. 14, 2008.

GUIMARÃES, Iolanda. Violência de gênero. In: LIMA, Cláudia Araújo de. Violência faz mal à saúde. 2. reimp. Brasília: Ministério da Saúde, 2006.

HERNANDEZ, Carmen Osorio. Política de crédito rural com perspectiva de gênero: um meio de "empoderamento" para as mulheres rurais? 2009. $248 \mathrm{f}$. Tese (Doutorado em Desenvolvimento Rural) - Programa de Pós-graduação em Desenvolvimento Rural, Universidade Federal do Rio Grande do Sul, Porto Alegre, 2009.

HIRATA, Helena; KERGOAT, Danièle. Novas configurações da divisão sexual do trabalho. Cadernos de Pesquisa, v. 37, n. 132, set./dez. 2007.

KERGOAT, Danièle. Relações sociais de sexo e divisão sexual do trabalho. In: LOPES, Marta Júlia Marques; MEYER, Dagmar Estermann; WALDOW, Vera Regina. Gênero e Saúde, Porto Alegre: Artes Médicas, 1996.

Dinâmica e consubstancialidade das relações sociais. Revista Novos Estudos, São Paulo, n. 86, p. 93-103, 2010.

LOPES, Marta Julia Marques. Violência contra mulheres rurais em áreas rurais sob o olhar da saúde. In: GERHARDT, Tatiana Engel; LOPES, Marta Julia Marques (Org.). O Rural e a Saúde: compartilhando teoria e método. Porto Alegre: Ed. da UFRGS, 2015. p. 77-85.

LORENZONI, Carmen. Violência nas relações de gênero e classe: uma interpretação a partir das mulheres camponesas do Rio Grande do Sul. Libertas, Juiz de Fora, Ed. especial, p. 82-98, 2007.

LUNARDI, Raquel. Mudanças nas relações de trabalho e gênero no turismo rural. 2012. 220 f. Tese (Doutorado em Desenvolvimento Rural) - Programa de Pós-graduação em Desenvolvimento Rural, Universidade Federal do Rio Grande do Sul, Porto Alegre, 2012. 
MINAYO, Cecília de Souza. O desafio da pesquisa social. In: DESLANDES, Suely Ferreira; MINAYO, Cecília de Souza. Pesquisa Social: teoria, método e criatividade. 26. ed. Petrópolis: Vozes, 2007.

RAUBER, Cassiane da Costa. Masculinização da população rural no Rio Grande do Sul: análise a partir dos sistemas agrários. 2010. 114 f. Dissertação (Mestrado em Extensão Rural) - Programa de Pós-graduação em Extensão Rural, Universidade Federal de Santa Maria, Santa Maria, 2010.

RIBEIRO, Claudio Marques. Estudo do modo de vida dos pecuaristas familiares da Região da Campanha do Rio Grande do Sul. 2009. 303 f. Tese (Doutorado em Desenvolvimento Rural) - Programa de Pós-graduação em Desenvolvimento Rural, Universidade Federal do Rio Grande do Sul, Porto Alegre, 2009.

SANDRINI, Gisléia Benini Duarte. Processo de inserção dos pecuaristas familiares do Rio Grande do Sul, na cadeia produtiva da carne. 2005. 175 f. Dissertação (Mestrado em Desenvolvimento Rural) - Programa de Pós-graduação em Desenvolvimento Rural, Universidade Federal do Rio Grande do Sul, Porto Alegre, 2005.

SCHNEIDER, Sergio. Situando o desenvolvimento rural no Brasil: o contexto e as questões em debate. Revista de Economia Política, v. 30, n. 3, p. 511-531, jul./ set. 2010.

SEN, Amartya Kumar. A condição de agente das mulheres e a mudança social. In: SEN, Amartya Kumar. Desenvolvimento como liberdade. 7. reimpr. São Paulo: Companhia das Letras, 2000.

TEDESCHI, Losandro Antônio. Meu nome é "ajuda": a vida cotidiana e as relações de poder, gênero e trabalho das mulheres trabalhadoras rurais na região Noroeste do Rio Grande do Sul. Contexto e Educação, v. 19, n. 71/72, p. 45-64, jan./dez. 2004.

A poderosa "mão invisível" da vida cotidiana: reflexões sobre gênero e trabalho na história das mulheres camponesas. História e Perspectivas, v. 49, p. 439-457, jul./dez. 2013.

ZORZI, Analisa. Uma análise crítica da noção de empoderamento com base no acesso das agricultoras ao PRONAF Mulher em Ijuí-RS. 2008. 137 f. Dissertação (Mestrado em Sociologia) - Programa de Pós-graduação em Sociologia, Universidade Federal do Rio Grande do Sul, Porto Alegre, 2008.

Submetido em: 25/04/2018

Aceito em: 07/08/2018 


\title{
DIRECTIONS OF COMBINING AND SHARING: INEQUALITIES AND VULNERABILITY SITUATIONS OF WOMEN IN THE FAMILY LIVESTOCK
}

\begin{abstract}
The purpose of this article is to present and discuss working conditions and family dynamics in family livestock breeding, which constitute situations of vulnerability and deprivation of rights of women participating in an academic research. Also it is dedicated to show situations that configure different types of violence suffered. Theoretically presents a reading with contemporary authors dedicated to thinking about the sexual division of labor, as well as violence in the rural beyond reflections inspired by the French sociologist Pierre Bourdieu. It was based on a qualitative research, of the case study type, in which the thematic content of 15 interviews was analyzed. The categories defined and analyzed in this article were: community integration; distribution and destination of income and agricultural credit. The discussion allowed the understanding that some structural elements of work in livestock and, certain family dynamics, are potential generators of vulnerabilities to women confirming the persistence of an asymmetric and hierarchical system of gender relations. The analyzes point to situations that suggest the pertinence of new perspectives on the classic masculine determinations of family livestock, defined by the economic autonomy, professional qualification in disregarded areas for women, among others.
\end{abstract}

Keywords: Gender. Family livestock. Vulnerabilities. Sexual division of labor. 